\title{
Saccharomyces cerevisiae Catalyzed Cyclocondensation Reaction: Synthesis of Pyrazoline
}

\author{
Nitesh D. Punyapreddiwar, Atul V. Wankhade, Sangesh P. Zodape, and Umesh R. Pratap \\ Department of Chemistry, Visvesvaraya National Institute of Technology, Nagpur, Maharashtra 440010, India \\ Correspondence should be addressed to Umesh R. Pratap; umeshpratap2014@gmail.com
}

Received 14 July 2016; Revised 31 August 2016; Accepted 1 September 2016

Academic Editor: Guang-Fu Yang

Copyright (c) 2016 Nitesh D. Punyapreddiwar et al. This is an open access article distributed under the Creative Commons Attribution License, which permits unrestricted use, distribution, and reproduction in any medium, provided the original work is properly cited.

\begin{abstract}
A simple, efficient, and environment friendly method has been developed for the synthesis of pyrazoline by the cyclocondensation of chalcones and hydrazine hydrate using very cheaper catalyst, baker's yeast (Saccharomyces cerevisiae). The 3,5-diphenyl pyrazolines are synthesized in moderate to good yield. The method also overcomes drawbacks of the previous pyrazoline synthetic methods and provides a new efficient route to 3,5-diphenyl pyrazoline derivatives.
\end{abstract}

\section{Introduction}

The pyrazolines are important nitrogen containing heterocyclic compounds possessing various pharmacological activities and therefore they are useful material in pharmaceutical industry for drug development [1-3].

2-Pyrazoline is present in number of pharmacological active molecules such as Phenazone, Methampyrone, Azolid, Tandaril, Indoxacarb, and Anturane, and they are useful as analgesic, antipyretic, anti-inflammatory, and insecticidal $[4$, 5].

Triaryl pyrazoline is showing antidepressant activity and also inhibits the flavivirus infection of cell culture and was identified through high-throughput screening of compound library using luciferase west Nile virus [6].

Amir et al. [7] synthesized a series of 3-(4-biphenyl)5-substituted phenyl-2-pyrazolines and 1-benzoyl-3-(4biphenyl)-5-substituted phenyl-2-pyrazolines and screened them for their anti-inflammatory and analgesic activity. Gökhan-Kelekçi et al. [8] have synthesized a new series of pyrazoline derivatives and evaluated them for antidepressant, anxiogenic, and MAO-A and MAO-B inhibitory activities by in vivo and in vitro tests, respectively. Palaska et al. [9] synthesized 3,5-diphenyl-2-pyrazoline derivatives and evaluated their antidepressant activities by the "Porsolt Behavioral Despair Test" on Swiss Webster mice.
In view of the applications of 3,5-diphenyl pyrazolines, various methods are available for their synthesis using different catalysts like acetic anhydride [10], pyridine [11], and acetic acid [12].

The above-mentioned catalysts suffer from drawbacks like need of elevated temperature, longer time, and some catalysts which are hazardous; that is why green method for the synthesis of pyrazoline is required. Till date there is not any biocatalytical method reported; therefore we have developed baker's yeast catalyzed protocol for the cyclocondensation of chalcone and hydrazine hydrate to obtain pyrazolines.

Nowadays biocatalysis is playing vital role in organic synthesis; however, among those baker's yeast is whole cell biocatalyst, used for various organic reactions, for example, Michael addition [13], Aldol reaction [14], Henry reaction [15], and Knoevenagel condensation [16, 17]

The nonaqueous biocatalysis in organic solvent offers various advantages like solubility of organic substrates, easy workup, and isolation of the product and sometimes reusability of biocatalysts [15, 18-22].

Considering the above facts, we have developed an efficient methodology for synthesis of pyrazoline from chalcone and hydrazine hydrate in organic solvent by using inexpensive biocatalyst, baker's yeast. 


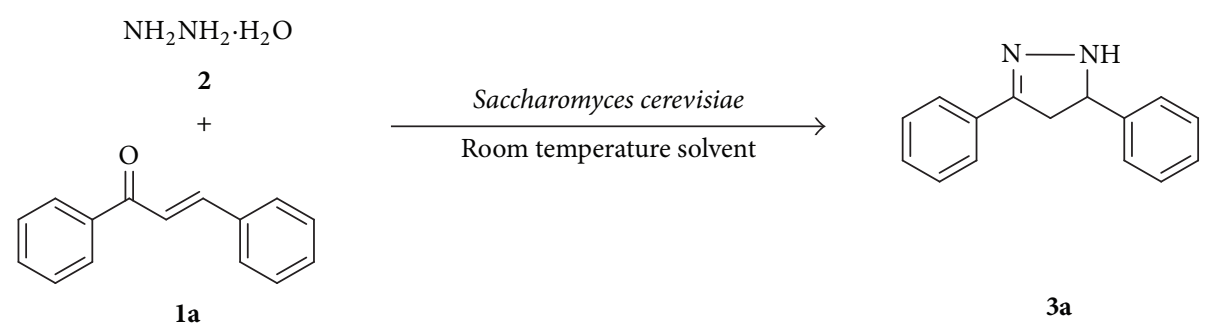

SCHEME 1

\section{Materials and Methods}

2.1. Materials. All chemicals were purchased from commercial suppliers and used as they are. ${ }^{1} \mathrm{H}$ NMR and ${ }^{13} \mathrm{C}$ NMR Spectra were recorded on Bucker Advance II $400 \mathrm{MHz}$ spectrometer at ambient temperatures in $\mathrm{CDCl}_{3}$ as solvent. Thin layer chromatography was carried out using Merk's silica plates. The dry baker's yeast is purchased from local market.

2.2. Method: General Experimental Procedure for Synthesis of Pyrazolines $(3 \boldsymbol{a}-\boldsymbol{m})$. To the mixture of chalcone $(5 \mathrm{mmol})$ and hydrazine hydrate $(10 \mathrm{mmol})$ in methanol $(15 \mathrm{~mL})$, baker's yeast $(2 \mathrm{~g}$ ) was added. The resulting reaction mixture was continuously stirred at room temperature on magnetic stirrer. The progress of the reaction was monitored by thin layer chromatography using petroleum ether: ethyl acetate $(3: 1)$. After completion of the reaction $(32 \mathrm{~h})$, reaction mixture was filtered using silica bed to remove the catalyst and washed with methanol $(50 \mathrm{~mL})$. The reaction mixture was concentrated under vacuum and obtained crude products. The purification was done by recrystallization in ethanol.

\subsection{Spectral Data of Compounds}

N,N-Dimethyl-4-(3-phenyl-4,5-dihydro-1H-pyrazol-5-yl)aniline (3d). ${ }^{1} \mathrm{H} \mathrm{NMR}-\left(400 \mathrm{MHz}, \mathrm{CDCl}_{3}\right) \delta$ (ppm) $2.86(\mathrm{~s}, 6 \mathrm{H})$, $3.29(\mathrm{dd}, 1 \mathrm{H}), 4.76(\mathrm{dd}, 1 \mathrm{H}), 6.65(2 \mathrm{H}, \mathrm{d}, J=7.78 \mathrm{~Hz}), 7.19$ $(\mathrm{d}, 2 \mathrm{H}, J=7.80 \mathrm{~Hz}), 8.12(1 \mathrm{H}, \mathrm{t}, J=7.78 \mathrm{~Hz}), 8.32(\mathrm{t}, 2 \mathrm{H}$, $J=7.60 \mathrm{~Hz}), 8.62(\mathrm{~d}, 2 \mathrm{H}, J=8.58 \mathrm{~Hz}) .{ }^{13} \mathrm{C} \mathrm{NMR}-(100 \mathrm{MHz}$, $\left.\mathrm{CDCl}_{3}\right) \delta(\mathrm{ppm})$ 39.87, 63.41, 78.79, 112.27, 125.21, 127.88, $127.74,128.24,130.23,133.27,148.58,149.70$.

4,5-Dihydro-5-(4-Methoxyphenyl)-3-Phenyl-1H-Pyrazole (3h). ${ }^{1} \mathrm{H} \mathrm{NMR}-\left(400 \mathrm{MHz}, \mathrm{CDCl}_{3}\right) \delta(\mathrm{ppm}) 2.72(\mathrm{dd}, 1 \mathrm{H}), 3.72(\mathrm{~S}$, $3 \mathrm{H}), 3.76(\mathrm{dd}, 1 \mathrm{H}), 4.67(\mathrm{dd}, 1 \mathrm{H}), 6.74-8.13(\mathrm{~m}, 8 \mathrm{H}), 9.64(\mathrm{~s}$, 1H), 10.22 (s, 1H). ${ }^{13} \mathrm{C} \mathrm{NMR}-\left(100 \mathrm{MHz}, \mathrm{CDCl}_{3}\right) \delta(\mathrm{ppm})=$ 25.0, 55.0, 62.9, 113.7, 114.1, 115.3, 115.5, 129.3, 126.3, 127.0, 127.7, $129.3,129.7,130.5,149.5,157.75$.

\section{Result and Discussion}

Herein, we report an efficient and economic synthesis of pyrazoline from chalcone and hydrazine hydrate under mild conditions catalyzed by baker's yeast. Resulting products are obtained in high yields in methanol. The chalcones are prepared by the reaction of substituted acetophenones and benzaldehydes in the presence of sodium hydroxide in aqueous ethanol $[23,24]$.
TABLE 1: Effect of solvent on synthesis of pyrazoline catalyzed by baker's yeast ${ }^{\mathrm{a}}$.

\begin{tabular}{lccc}
\hline Entry & Solvent & Time $(\mathrm{h})$ & Yield $^{\mathrm{b}}(\%)$ \\
\hline $\mathbf{1}$ & Ethanol & 32 & 82 \\
$\mathbf{2}$ & Methanol & 32 & 86 \\
$\mathbf{3}$ & Ethanol + water & 32 & 70 \\
$\mathbf{4}$ & Methanol + water & 32 & 70 \\
$\mathbf{5}$ & can & 32 & 55 \\
$\mathbf{6}$ & DCM & 32 & 55 \\
$\mathbf{7}$ & DMF & 32 & 50 \\
$\mathbf{8}$ & DMSO & 32 & 57 \\
$\mathbf{9}$ & THF & 32 & 54 \\
\hline
\end{tabular}

${ }^{a}$ Reaction condition: chalcone $(5 \mathrm{mmol})$, hydrazine hydrate $(10 \mathrm{mmol})$, and baker's yeast $(2 \mathrm{~g})$ in solvent $(15 \mathrm{~mL})$ under room temperature. ${ }^{\mathrm{b}}$ Isolated yields.

In order to get best experimental condition, we considered the reaction of chalcone and hydrazine hydrate using baker's yeast catalyst as model reaction (Scheme 1).

To have the best experimental results, baker's yeast was utilized as a catalyst in different organic solvents including polar protic, aprotic like ethanol $\left(\mathrm{C}_{2} \mathrm{H}_{5} \mathrm{OH}\right)$, methanol $\left(\mathrm{CH}_{3} \mathrm{OH}\right)$, acetonitrile $(\mathrm{ACN})$, dichloromethane (DCM), dimethylformamide (DMF), dimethyl sulphoxide (DMSO), and tetrahydrofuran (THF) as well as aqueous methanol and ethanol. The reaction proceeds in all anhydrous and hydrous organic solvents (Table 1, entries 1-9).

From Table 1 it is concluded that the protic solvents are best for this reaction and among those methanol was found to be best solvent for this reaction because reactions required less time and high yield of product is obtained (Table 1, entry 2) as compared to other solvents. Therefore, methanol was selected as a solvent for further study. Model reaction was carried out in the absence of catalyst in methanol but there no conversion takes place even after $32 \mathrm{hrs}$ (Table 2, entry 1).

Then model reaction was forwarded using different amount of catalyst, starting with $0.5 \mathrm{~g}$ baker's yeast but there was no formation of product in 32 hours. When $1 \mathrm{~g}$ of baker's yeast was used, 35\% yield in 32 hours is obtained. $2 \mathrm{~g}$ baker's yeast gives $89 \%$ yield, and $3 \mathrm{~g}$ and $4 \mathrm{~g}$ baker's yeast get $90 \%$ yield in $32 \mathrm{hrs}$. Though increased amount of catalysts yielded $90 \%$ of product but it required more solvent $(20 \mathrm{~mL})$ because $3 \mathrm{~g}$ and $4 \mathrm{~g}$ of catalyst were difficult to stir in $15 \mathrm{~mL}$ of methanol. We analyzed the yield after isolation of product (3a); we considered that model reactions with $2 \mathrm{~g}$ of baker's 


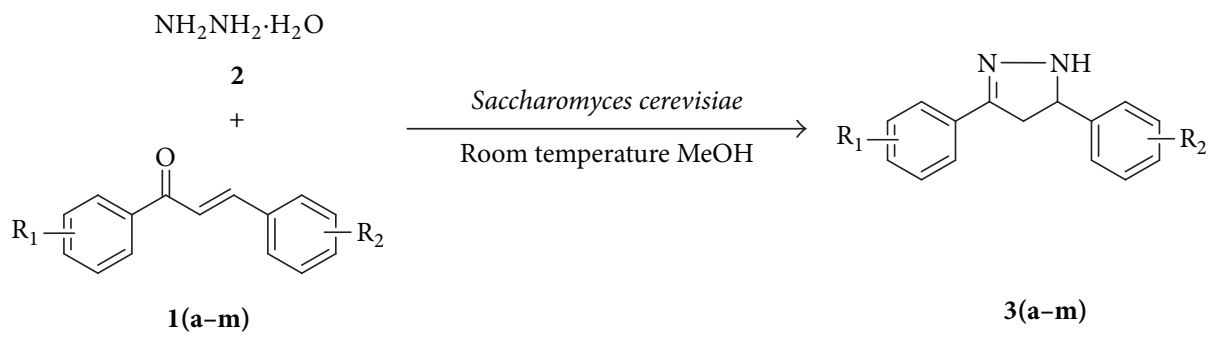

SCHEME 2: Synthesis of pyrazoline derivatives.

TABLE 2: Effect of amount of catalyst on the synthesis of pyrazoline ${ }^{\mathrm{a}}$.

\begin{tabular}{lccc}
\hline Entry & Catalyst $(\mathrm{g})$ & Time $(\mathrm{h})$ & Yield $^{\mathrm{b}}(\%)$ \\
\hline $\mathbf{1}$ & - & 32 & 00 \\
$\mathbf{2}$ & 0.5 & 32 & 00 \\
$\mathbf{3}$ & 1 & 32 & 30 \\
$\mathbf{4}$ & 2 & 32 & 89 \\
$\mathbf{5}$ & 3 & 32 & 90 \\
$\mathbf{6}$ & 4 & 32 & 90 \\
\hline
\end{tabular}

${ }^{a}$ Reaction condition: chalcone $(5 \mathrm{mmol})$, hydrazine hydrate $(10 \mathrm{mmol})$, and baker's yeast in methanol $(15 \mathrm{~mL})$ at room temperature. ${ }^{\mathrm{b}}$ Isolated yield.

TABLE 3: Baker's yeast catalyzed synthesis of pyrazoline derivatives in organic solvent ${ }^{\mathrm{a}}$.

\begin{tabular}{lcccc}
\hline S. N. & $\mathrm{R}_{1}$ & $\mathrm{R}_{2}$ & Product & Yield $^{\mathrm{b}}(\%)$ \\
\hline $\mathbf{1}$ & $\mathrm{H}$ & $\mathrm{H}$ & $\mathbf{3 a}$ & 86 \\
$\mathbf{2}$ & $\mathrm{H}$ & $4-\mathrm{Cl}$ & $\mathbf{3 b}$ & 88 \\
$\mathbf{3}$ & $\mathrm{H}$ & $4-\mathrm{NO}_{2}$ & $\mathbf{3 c}$ & 82 \\
$\mathbf{4}$ & $\mathrm{H}$ & $4-\mathrm{N}^{\left.-\mathrm{CH}_{3}\right)}$ & $\mathbf{3 d}$ & 86 \\
$\mathbf{5}$ & $\mathrm{H}$ & $4-\mathrm{OCH}_{3}$ & $\mathbf{3 e}$ & 78 \\
$\mathbf{6}$ & $4-\mathrm{OH}$ & $\mathrm{H}$ & $\mathbf{3 f}$ & 75 \\
$\mathbf{7}$ & $4-\mathrm{OH}$ & $4-\mathrm{Cl}$ & $\mathbf{3 g}$ & 76 \\
$\mathbf{8}$ & $4-\mathrm{OH}$ & $4-\mathrm{OCH}$ & $\mathbf{3 h}$ & 84 \\
$\mathbf{9}$ & $2-\mathrm{OH}$ & $\mathrm{H}$ & $\mathbf{3 i}$ & 78 \\
$\mathbf{1 0}$ & $2-\mathrm{OH}$ & $4-\mathrm{N}\left(\mathrm{CH}_{3}\right)_{2}$ & $\mathbf{3 j}$ & 82 \\
$\mathbf{1 1}$ & $2-\mathrm{OH}$ & $4-\mathrm{Cl}_{1}$ & $\mathbf{3 k}$ & 78 \\
$\mathbf{1 2}$ & $3,4 \mathrm{OCH}_{3}$ & $\mathrm{H}$ & $\mathbf{3 1}$ & 68 \\
$\mathbf{1 3}$ & $3,4 \mathrm{OCH}_{3}$ & $4-\mathrm{Cl}$ & $\mathbf{3 m}$ & 66 \\
\hline
\end{tabular}

${ }^{a}$ Reaction condition: chalcone $(5 \mathrm{mmol})$, hydrazine hydrate $(10 \mathrm{mmol})$, and baker's yeast $(2 \mathrm{~g})$ in methanol $(15 \mathrm{~mL})$ under room temperature at $32 \mathrm{~h}$. ${ }^{\mathrm{b}}$ Isolated yield.

yeast in methanol are the best because of higher yield in less amount of solvent and catalyst (Table 2, entries 2-5).

To generalize the methodology, the variety of chalcones reacted with hydrazine hydrate using baker's yeast $(2 \mathrm{~g})$ in methanol (Table 3, entries 1-13).

A variety of chalcones containing electron donating and electron withdrawing group attached to either acetophenone ring or benzaldehyde ring or both the rings were successfully employed to prepare corresponding products. Firstly simple acetophenone with benzaldehydes, 4-chloro, 4-nitro, 4-N,N dimethyl amine, and 4-methoxy substituted benzaldehydes containing chalcone to give desired products in good to better yields, (Table 3, entries 1-5), and then 4-hydroxyacetophenone with benzaldehyde and 4-chloro and 4-methoxy substituted benzaldehyde ring containing chalcone to give good yield of the products, (Table 3, entries 6-8) and then the chalcones of 2-hydroxyacetophenone and 4-chloro and 4-N,N-dimethyl substituted benzaldehyde successfully and yielded the pyrazolines, (Table 3, entries 9-11) and when the chalcone prepared from 4-methoxy acetophenone and 4-chlorobenzaldehyde is allowed to react with hydrazine hydrate in the presence of baker's yeast, it gives good yield of the corresponding pyrazoline (Table 3, entries 12-13 and Scheme 2).

\section{Conclusion}

In summary, here baker's yeast is successfully employed to synthesize value added heterocycle, pyrazoline from chalcone in organic solvent, with moderate to good yield under mild conditions. The highlight of this work is the cost effectiveness and eco-friendliness.

\section{Competing Interests}

The authors declare that there are no competing interests regarding the publication of this paper. The mentioned received funding in the Acknowledgments section does not have any competing interests regarding the publication of this manuscript.

\section{Acknowledgments}

The authors are thankful to Science and Engineering Research Board, New Delhi, for providing financial support. They are also grateful to Professor R. A. Mane for valuable guidance. The authors are thankful to SAIF, Chandigarh University, for providing spectral characterizations.

\section{References}

[1] G. Turan-Zitouni, P. Chevallet, F. S. Kiliç, and K. Erol, "Synthesis of some thiazolyl-pyrazoline derivatives and preliminary investigation of their hypotensive activity," European Journal of Medicinal Chemistry, vol. 35, no. 6, pp. 635-641, 2000.

[2] J. H. Ahn, H.-M. Kim, S. H. Jung et al., "Synthesis and DP-IV inhibition of cyano-pyrazoline derivatives as potent 
anti-diabetic agents," Bioorganic and Medicinal Chemistry Letters, vol. 14, no. 17, pp. 4461-4465, 2004.

[3] D. Havrylyuk, B. Zimenkovsky, O. Vasylenko, L. Zaprutko, A. Gzella, and R. Lesyk, "Synthesis of novel thiazolone-based compounds containing pyrazoline moiety and evaluation of their anticancer activity," European Journal of Medicinal Chemistry, vol. 44, no. 4, pp. 1396-1404, 2009.

[4] K. S. Silver and D. M. Soderlund, "Action of pyrazoline-type insecticides at neuronal target sites," Pesticide Biochemistry and Physiology, vol. 81, no. 2, pp. 136-143, 2005.

[5] R. Sasikala, K. Thirumurthy, P. Mayavel, and G. Thirunarayanan, "Eco-friendly synthesis and antimicrobial activities of some 1-phenyl-3(5-bromothiophen-2-yl)-5-(substituted phenyl)-2pyrazolines," Organic and Medicinal Chemistry Letters, vol. 2, no. 1, article 20, pp. 1-13, 2012.

[6] A. Ahmad, A. Husain, S. A. Khan, M. Mujeeb, and A. Bhandari, "Synthesis, antimicrobial and antitubercular activities of some novel pyrazoline derivatives," Journal of Saudi Chemical Society, vol. 20, no. 5, pp. 577-584, 2016.

[7] M. Amir, H. Kumar, and S. A. Khan, "Synthesis and pharmacological evaluation of pyrazoline derivatives as new antiinflammatory and analgesic agents," Bioorganic and Medicinal Chemistry Letters, vol. 18, no. 3, pp. 918-922, 2008.

[8] N. Gökhan-Kelekçi, S. Koyunoğlu, S. Yabanoğlu et al., "New pyrazoline bearing $4(3 \mathrm{H})$-quinazolinone inhibitors of monoamine oxidase: synthesis, biological evaluation, and structural determinants of MAO-A and MAO-B selectivity," Bioorganic \& Medicinal Chemistry, vol. 17, no. 2, pp. 675-689, 2009.

[9] E. Palaska, M. Aytemir, I. T. Uzbay, and D. Erol, "Synthesis and antidepressant activities of some 3,5-diphenyl-2-pyrazolines," European Journal of Medicinal Chemistry, vol. 36, no. 6, pp. 539543, 2001.

[10] B. A. Bhat, S. C. Puri, and M. A. Qurishi, "Synthesis of 3,5-diphenyl-1 H -pyrazoles," Synthetic Communications, vol. 35, no. 8, pp. 1135-1142, 2005.

[11] M. Johnson, B. Younglove, L. Lee et al., "Design, synthesis, and biological testing of pyrazoline derivatives of combretastatinA4," Bioorganic and Medicinal Chemistry Letters, vol. 17, no. 21, pp. 5897-5901, 2007.

[12] R. Gupta, N. Gupta, and A. Jain, "Improved synthesis of chalcones and pyrazolines under ultrasonic irradiation," Indian Journal of Chemistry -Section B: Organic and Medicinal Chemistry, vol. 49, no. 3, pp. 351-355, 2010.

[13] N. G. Singh, R. Nongrum, C. Kathing, J. W. S. Rani, and R. Nongkhlaw, "Bakers' yeast: an environment benign catalyst for the one-pot synthesis of indolyl chromenes and bisindolyl alkanes," Green Chemistry Letters and Reviews, vol. 7, no. 2, pp. 137-144, 2014.

[14] C. Li, X. Feng, and N. Wang, "Biocatalytic promiscuity: the first lipase-catalysed asymmetric aldol reaction," Green Chemistry, vol. 10, pp. 616-618, 2008.

[15] A. Kumar and R. A. Maurya, "An efficient bakers' yeast catalyzed synthesis of 3,4-dihydropyrimidin-2-(1H)-ones," Tetrahedron Letters, vol. 48, no. 26, pp. 4569-4571, 2007.

[16] U. R. Pratap, D. V. Jawale, R. A. Waghmare, D. L. Lingampalle, and R. A. Mane, "Synthesis of 5-arylidene-2,4-thiazolidinediones by Knoevenagel condensation catalyzed by baker's yeast," New Journal of Chemistry, vol. 35, no. 1, pp. 49-51, 2011.

[17] U. R. Pratap, D. V. Jawale, B. S. Londhe, and R. A. Mane, "Baker's yeast catalyzed synthesis of 1,4-benzothiazines, performed under ultrasonication," Journal of Molecular Catalysis B: Enzymatic, vol. 68, no. 1, pp. 94-97, 2011.
[18] U. R. Pratap, D. V. Jawale, P. D. Netankar, and R. A. Mane, "Baker's yeast catalyzed one-pot three-component synthesis of polyfunctionalized 4H-pyrans," Tetrahedron Letters, vol. 52, no. 44, pp. 5817-5819, 2011.

[19] U. R. Pratap, J. R. Mali, D. V. Jawale, and R. A. Mane, "Bakers' yeast catalyzed synthesis of benzothiazoles in an organic medium," Tetrahedron Letters, vol. 50, no. 12, pp. 1352-1354, 2009.

[20] A. Özdemir, G. Turan-Zitouni, Z. Asim Kaplancikli, G. Revial, and K. Güven, "Synthesis and antimicrobial activity of 1-(4aryl-2-thiazolyl)-3-(2-thienyl)-5-aryl-2-pyrazoline derivatives," European Journal of Medicinal Chemistry, vol. 42, no. 3, pp. 403409, 2007.

[21] A. Wolfson, C. Dlugy, D. Tavor, J. Blumenfeld, and Y. Shotland, "Baker's yeast catalyzed asymmetric reduction in glycerol," Tetrahedron Asymmetry, vol. 17, no. 14, pp. 2043-2045, 2006.

[22] H. N. Borah, D. Prajapati, and R. C. Boruah, "Bakers' yeastcatalyzed ring opening of benzofuroxans: an efficient green synthesis of aryl-1,2-diamines," Synthetic Communications, vol. 39, no. 2, pp. 267-272, 2009.

[23] B. A. Bhat, K. L. Dhar, S. C. Puri, A. K. Saxena, M. Shanmugavel, and G. N. Qazi, "Synthesis and biological evaluation of chalcones and their derived pyrazoles as potential cytotoxic agents," Bioorganic and Medicinal Chemistry Letters, vol. 15, no. 12, pp. 3177-3180, 2005.

[24] S. Singh, P. K. Sharma, N. Kumar, and R. Dudhe, "Antioxidant activity of 2-hydroxyacetophenone chalcone," Journal of Advanced Scientific Research, vol. 2, no. 3, pp. 37-41, 2011. 

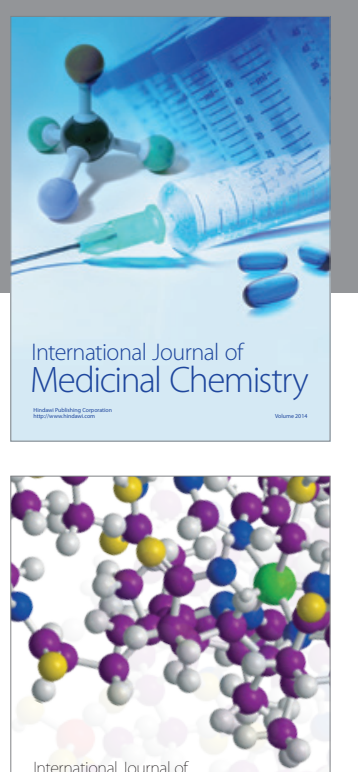

Carbohydrate Chemistry

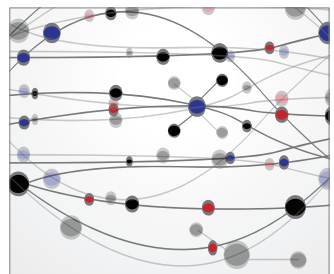

The Scientific World Journal
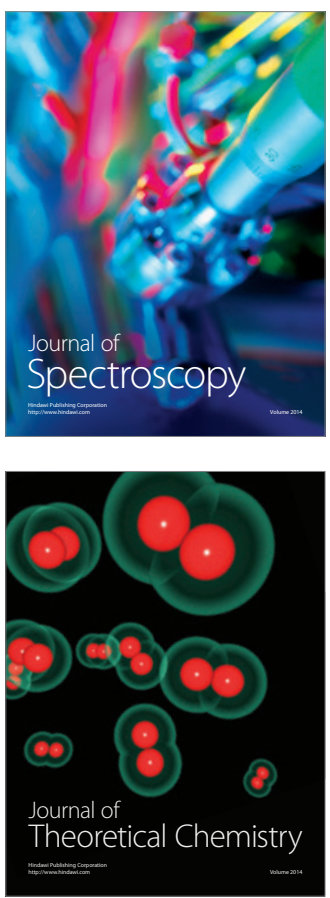
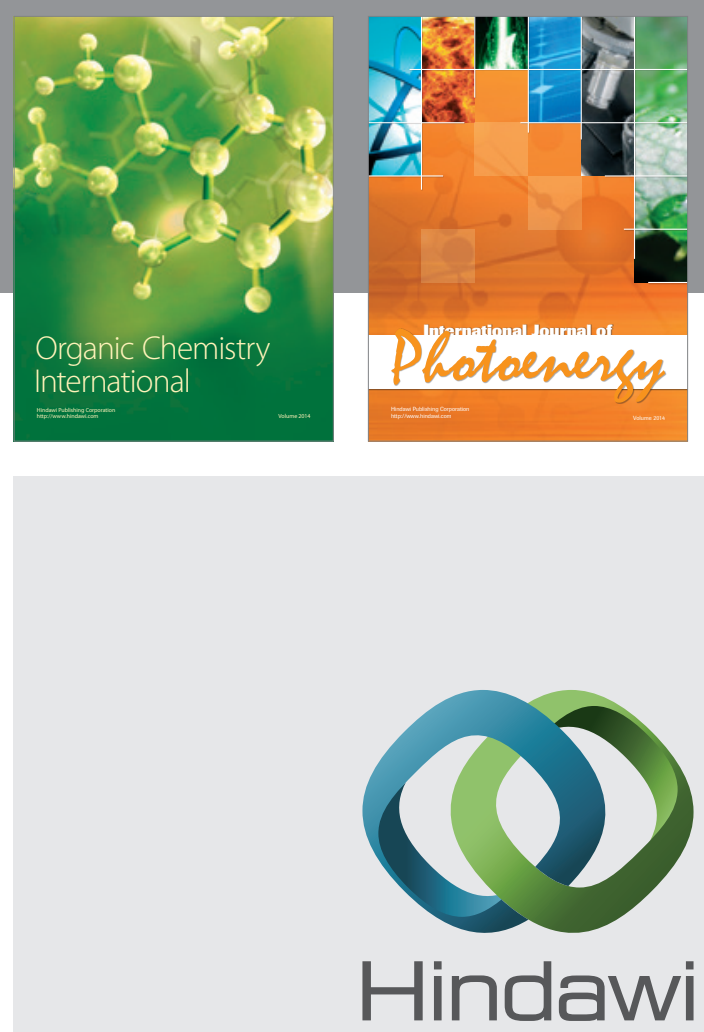

Submit your manuscripts at

http://www.hindawi.com

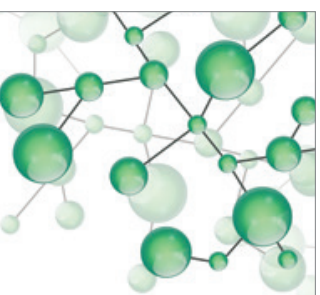

International Journal of

Inorganic Chemistry

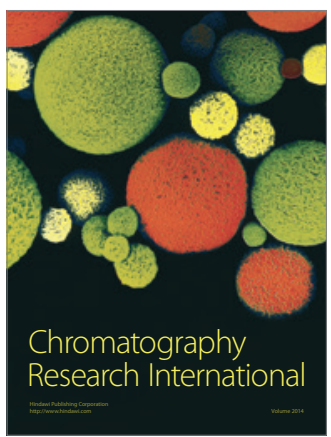

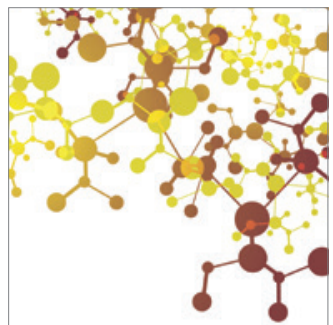

Applied Chemistry
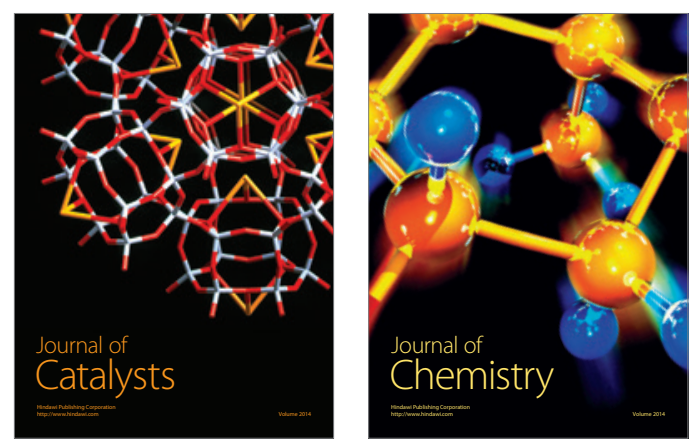
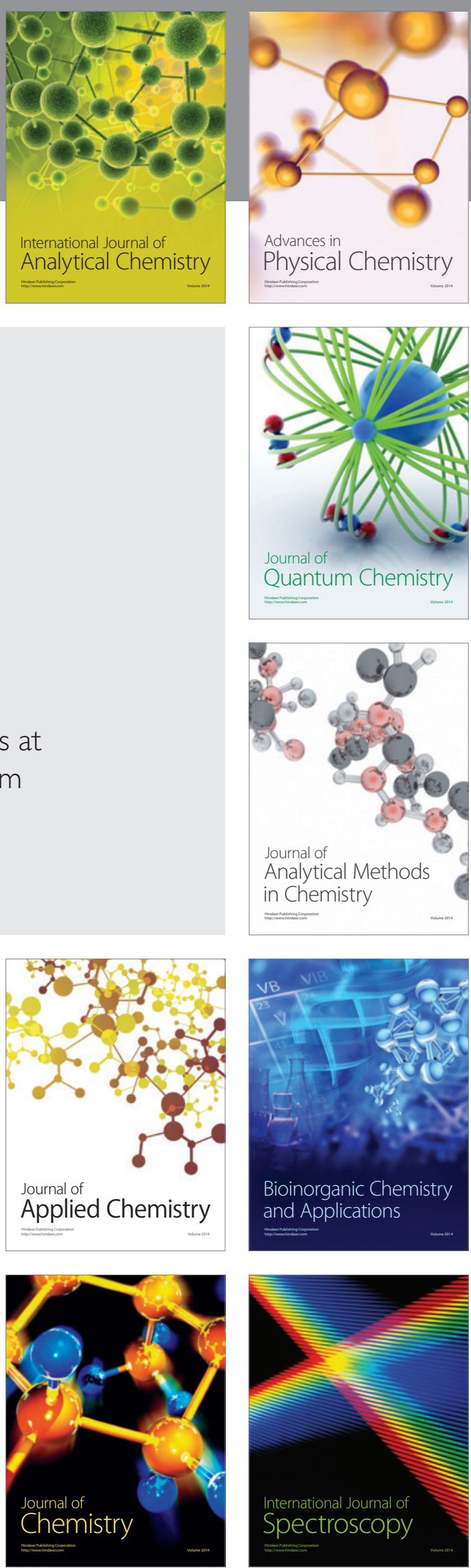